\title{
Rethinking Fireproof Houses-The Problem of Wildland Fires
}

ISSN: 2639-0574

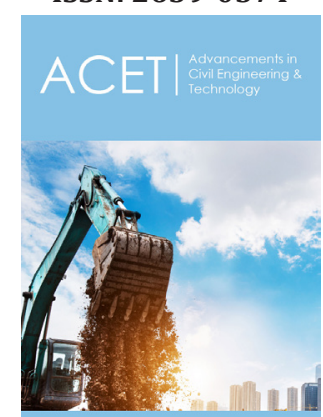

${ }^{* 1}$ Corresponding author: Brancob F, Full Professor, Portugal

Submission: 眥 July 17, 2019

Published: 蹧July 19, 2019

Volume 3 - Issue 3

How to cite this article: Tenreiroa $\mathrm{T}$, Brancob F, Arrudac MRT. Rethinking Fireproof Houses-The Problem of Wildland Fires. Adv Civil Eng Tech. 3(3). ACET.000565.2019.

DOI: 10.31031/ACET.2019.03.000565

Copyright@ Brancob F, This article is distributed under the terms of the Creative Commons Attribution 4.0 International License, which permits unrestricted use and redistribution provided that the original author and source are credited.

\author{
Tenreiroa $\mathrm{T}^{1}$, Brancob $^{2 *}$ and Arrudac $\mathrm{MRT}^{3}$ \\ ${ }^{1}$ MSc Student, IST, Portugal \\ ${ }^{2}$ Full Professor, Portugal \\ ${ }^{3}$ Research Associate, Portugal
}

\section{Abstract}

In recent years, fires had a major impact on the forest, mostly due to high combustibility of the wildland and to climate change. Fires spread to the wildland-urban interface, due to wind effects and poor urban forest area management, causing severe lasting damage or even the destruction of dwellings. This paper presents a summary analysis on solutions for new houses ("fireproof houses") using current building materials but with characteristics to maintain the overall structure for a longer time during a wildland fire exposure.

\section{Introduction}

Global warming and climate change have caused more often the occurrence of wildland fires (WLF), during the summer, in the Mediterranean Europe, California and Australia, mainly in large unattended forest areas or without significant population occupation. In addition to the damage caused in the forest, these fires cause the destruction of dwellings and occasionally lead to the death of residents. It is therefore necessary to implement constructive preventive measures. The risk of wildland fires in Portugal has increased in the last 10 years due to climate change and the unguarded plantation of the forest (eucalyptus and pine). The north and central zone of Portugal (with large forest vegetation), are the areas that were more heavily affected by the biggest wildland fires (WLF) from 1996 to 2009, due to the existence of fire spread mechanisms, mainly fuel and topography. In 2017, two of the largest wildland fires (WLF) recorded in the history of Portugal ("Pedrógão Grande" and "October 15th") had a major impact not only on the forest areas (burning 45.000 ha+241.000ha, respectively) [1,2], but also on the communities with a death toll of 114 .

Following these fires, new legislation was created [3], concerning measures related to the wildland urban (WUI) interface (forest cleaning, vegetation height, distance from vegetation to dwellings, etc....). Surprisingly no extra measure or care was taken, regarding the characteristics of the dwellings or the protection of the people caught by the fires. However, the analysis of expert opinions and inquiries [1,4,2], clearly showed that the dwellings that had burned, had constructive typologies without any passive "fire" protection. The disregard of this aspect, led to the burned houses being rebuilt in the same way as the original, which means that they are likely to burn again in the next wildland fire. This important blank in protection measures of houses against wildland fires, led to the development of recommendations highlighted in this work [4].

\section{Inquiries About Fire-House Interaction}

In order to characterize the building typologies of the burned houses, and their interaction with the occurred fires, information was collected in reports and studies performed on the two large WLF occurred in Portugal in 2017: Pedrógão Grande [2] and 15 de October [1]. The main conclusions were:

A. $61 \%$ of the structures were damaged (partially and totally) due to the firebrand propagation, but initial fires due to direct impact on the structures were only $21 \%$;

B. $62 \%$ of the fires occurred on the roof, not only due to the existence of vulnerable points, but also due to the strong wind that caused the roofs to be destroyed, exposing the interior of the structures;

C. In 23\% of damaged structures, fire started in windows and doors; 
D. About half of the fatalities were people that lost their lives when they tried to flee their homes, and it was later found that 21 of the 65 victims had no damage in their dwellings;

E. Many secondary small fires occurred from the projection of firebrands. Due to the strong wind, and the wild behaviour of the fire due to excessive fuel, there was a propagation of firebrands for more than $2.0 \mathrm{~km}$ away;

F. $\quad 93 \%$ of the homes that burned down completely, had a stone masonry structure with a wood structure in the roof covered with tiles, and only $7 \%$ had reinforced concrete structures with concrete slabs on the floors (Figure 1).

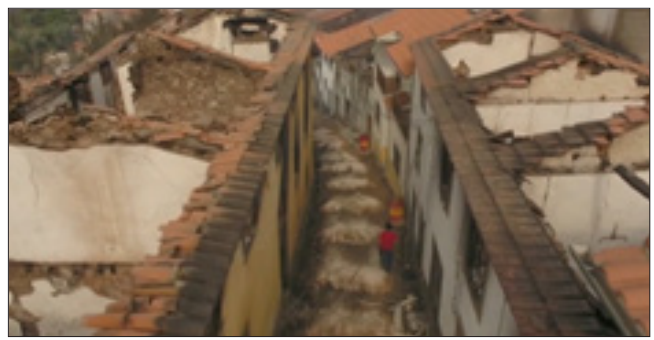

Figure 1: Example of old houses in which the roof burned, adapted from Portuguese press SIC.

\section{General measures proposed for the protection of houses}

The design of a "fireproof house" implies that: (i) it must withstand the near passage of a WLF; (ii) it must be protected against the entrance of firebrands; (iii) and, in urban situations, should be protected against the possible fire of nearby dwellings. The house must be able to endure an exterior fire so that its residents remain safely indoors for an estimated: firstly 30 minutes, associated with the maximum time passage of a WLF in an isolated house [5]; or secondly for about 60 minutes in case of nearby house that is burning as it did not resist a WLF $[6,7]$. It is important to point out, that contrary to normal ISO fire curves, a WLF possesses a maximum temperature of 800 to $900 \mathrm{oC}$ for 3 to 10 minutes period depending on the wind, fuel and topography [6], therefore, even if a WLF endures for 30 minutes its maximum temperature is clearly bellow the $950 \mathrm{oC}$, usually associated with 60 minutes of resistance in concrete and masonry bricks. This is achieved by the use of products and building elements, which have this fire-resistant capability, defined by standard fire tests (ISO 834-1).

\section{Fireproof houses}

To achieve solutions for "fireproof houses", several companies were contacted. All of them have studied several solutions with specific reworking of their products, which allowed formulating the referred proposals for a "fireproof house", in which the protection is guaranteed through an outer envelope (the walls, the roofs, the windows and doors). The house shall be able to withstand a fire after the suggested interventions so that its residents remain safe for at least one hour. A reinforced concrete structural solution of beams, columns, and slabs is recommended for "fireproof houses". This is due to the fact that reinforced concrete has a huge fire resistance. Exterior Walls-In concrete structures, exterior walls are typically built with brick masonry, and sometimes with concrete blocks, both with excellent fire behaviour, non-combustible and with low thermal conductivity. According to LNEC [8], ceramic materials have a significant advantage over other materials, which lies in the fact that they are non-combustible.

\section{Roof}

In new houses that are built with a sloped roof, to prevent the entrance of firebrands, it is recommended to adopt a solution of a reinforced concrete slab. The most common type of solution is a traditional prefabricated structural solution consisting of vaults with hollowed ceramic blocks, pre-stressed concrete joists, complemented with a fireproofing membrane, as well as rock wool insulation. An alternative solution to sloped roof, is the terraced solution with a reinforced concrete slab (or prefabricated beams) only with waterproofing, thermal insulation and a coating. The terraced solution allows the implementation of an active protective measure against nearby WLF, namely for the effect of firebrands. As it is shown in the left part of Figure 2, the system contains drains, a faucet, an overflow tube and a control button. It is assumed that a height of $2 \mathrm{~cm}$ of water is enough for the firebrands to rest on the water without damaging the roof structure. When the fire is extinguished, the control system can be switched off to drain the water.

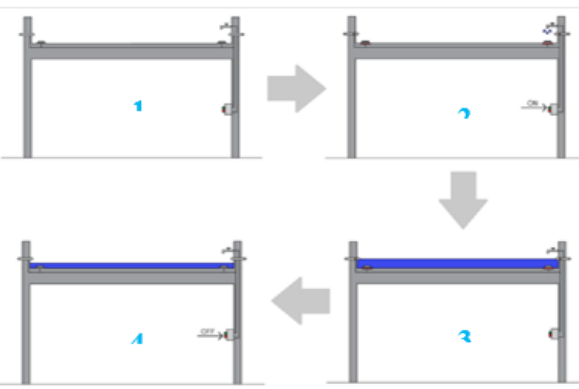

Figure 2: Components display and sequential procedure of the proposed water control system.

\section{Openings}

The shutters and covers made of aluminium were significant to prevent the entry of firebrands in the fire of Pedrógão Grande
[4]. The use of doors and window frames made of aluminium and a double glazing is a solution that may reduce the spread of a fire from outside. However, to enhance the fire resistance of aluminium shutter polyurethane should be inserted in its interior. 


\section{References}

1. Guerreiro J, Fonseca C, Salgueiro A, Fernandes P, Lopez IE, et al. (2018) Evaluation of the fires occurred between October 14 and 16, 2017 in mainland Portugal. Assembly of the Republic, Lisboa, Portugal.

2. Viegas DX, Almeida MF, Ribeiro LM (2017) The complex of fires of Pedrógão Grande and bordering counties, begun on June 17, 2017. Universidade de Coimbra, Portugal.

3. DL76/2017 (2017) Decreto Lei n.o 76/2017 Alteração do Sistema Nacional de Defesa da Floresta contra Incêndios. República, Ad Portugal, Diário da Republica Portuguesa 158: 4734-4762.

4. Tenreiro TC (2018) Construction techniques to protect houses from wildland fires. Lisbon, MSc, University of Lisbon, Instituto Superior Técnico, Portugal.
5. Mueller V (2016) Examination of the underlying physics in a detailed wildland fire behavior model through field-scale experimentation. Edinburgh, PhD, University of Edinburgh, Scotland, UK.

6. Pyne SJ, Andrews PL, Laven RD (1996) Introduction to Wildland Fire. John Wiley and Sons, UK.

7. Razdolsky L (2012) Structural Fire Loads: Theory and Principles. McGraw-Hill, USA.

8. LNEC (1990) National laboratory of civil engineering-E-364-Fire Safety. Fire resistance of building elements. Methods of Testing and Classification Criteria, Lisbon, Portugal. 